\title{
INTERDISCIPLINARIDADE: REFLEXÕES SOBRE PRÁTICAS PEDAGÓGICAS NO ENSINO MÉDIO INTEGRADO
}

\author{
Daguia de Medeiros Silva*, F. O. Araújo, R. G. Ferreira \\ *E-mail: wallacegilvania@hotmail.com \\ Instituto Federal de Educação, Ciência e Tecnologia do Rio Grande do Norte s \\ DOI: $10.15628 /$ rbept.2020.8813 \\ Artigo submetido em jul/2019 e aceito em fev/2020
}

\begin{abstract}
RESUMO
A interdisciplinaridade vem sendo de grande proeminência nas discussões no âmbito acadêmico. Muitas são as interpretações em relação ao termo da interdisciplinaridade tão difundidas nas práticas pedagógicas e muitas vezes confundidas com os termos da multi, pluridisciplinaridade. Nesse sentido, surgem questionamentos em relação a sua efetivação na sala de aula, considerando que a organização curricular das escolas se apresenta de forma disciplinar. Nessa perspectiva, o presente trabalho tem como objetivo reconhecer, em algumas práticas pedagógicas docentes, na sala de aula, a efetivação do princípio da interdisciplinaridade. Os caminhos percorridos para a efetivação da pesquisa se configuram numa abordagem qualitativa, caracterizando-se como estudo de caso. Para a coleta de dados foram utilizadas as técnicas da observação e a entrevista semiestruturada. Os sujeitos participantes da pesquisa foram docentes das disciplinas de Física, Biologia e Química que atuam no ensino médio integrado no IFRN Campus Currais Novos. Como resultado de pesquisa observou-se que os docentes são capazes de trabalhar de forma interdisciplinar na sala de aula sem que seja preciso desenvolver projetos interdisciplinares. Este, por sua vez, é mais uma forma de possibilitar práticas interdisciplinares onde os saberes dialogam entre si.
\end{abstract}

Palavras-Chave: Interdisciplinaridade. Práticas pedagógicas. Ensino Médio Integrado.

\section{INTERDISCIPLINARITY: REFLECTIONS ON PEDAGOGICAL PRACTICES IN INTEGRATED MIDDLE SCHOOL}

\begin{abstract}
Interdisciplinarity has been of great prominence in discussions in the academic field. There are many interpretations in relation to the term of interdisciplinarity so widespread in pedagogical practices and often confused with the terms of multi, multi and transdisciplinarity. In this sense, questions arise regarding its effectiveness in the classroom, considering that the organization of the schools curriculum presents in a disciplinary way. In this perspective, the present work aims to recognize, in some pedagogical teaching practices, in the classroom, the effectiveness of the principle of interdisciplinarity. The paths taken to carry out the research, are configured in the qualitative approach, characterizing itself as a case study. For data collection, observation techniques and semistructured interviews were used. The subjects that participated in the research were lecturers in the disciplines of Physics, Biology and Chemistry that IFRN-Campus Currais Novos. Throughout the development of this academic work, it can be observed that teachers are able to work with interdisciplinarity in the classroom, and that many interdisciplinary practices are developed in the school environment without the teacher perceiving.
\end{abstract}

Keywords: Interdisciplinarity. Pedagogical practices. Integrated High School. 


\section{INTRODUÇÃO}

O termo interdisciplinaridade vem sendo de grande relevância para as discussões no mundo acadêmico, porém, é importante destacar que essa temática não possui um sentido único e estável, deixando, portanto, múltiplas interpretações e compreensões.

No contexto atual da educação, nessa sociedade do conhecimento, é urgente repensar o papel da escola relacionado ao processo de ensino e de aprendizagem, entendendo-se que o ensino organizado de forma fragmentada, que privilegia a memorização de fatos e apresenta respostas prontas, não atende mais as expectativas desta sociedade.

Nesse contexto, observa-se que o tema "Interdisciplinaridade na prática docente" vem sendo discutido com mais força no mundo acadêmico e nas propostas educacionais vigentes, considerando a necessidade de integrar as disciplinas escolares e de contextualizar os conteúdos tornando-se consenso entre docentes e pesquisadores em educação.

Nesse processo, destaca-se a interdisciplinaridade como algo possível de integrar áreas de conhecimentos específicas, viabilizando uma interação entre as ciências com uma nova abordagem de determinados conteúdos, promovendo um maior dinamismo no processo de ensino e de aprendizagem e, porque não dizer uma maior interação entre o estudante, o professor e o conhecimento.

No entanto, observa-se que a interdisciplinaridade ainda é pouco praticada, devido a uma grande dificuldade em ser aplicada. Essa dificuldade talvez ocorra pela ausência de uma formação docente que contemple esses conhecimentos, sendo apontada como um dos fatores que interferem na efetivação de uma prática docente de forma interdisciplinar no âmbito da sala de aula.

Dessa forma, ressalta-se a importância da discussão recorrente desta temática, considerando que sua prática exige a utilização de novas abordagens metodológicas que envolvam conhecimentos de outras áreas e, nem todos os docentes estão preparados e com disponibilidade para trabalhar dessa forma.

Deste modo, é preciso que o professor desenvolva uma nova forma de pensar e agir que considere a rapidez e a abrangência das informações e 0 dinamismo do momento em que vivemos, envolvendo as várias áreas do conhecimento de forma articulada. Para tanto, faz-se necessário uma nova organização de tempo e de espaço, e nessa perspectiva, uma forma de ensinar é propiciar aos alunos o desenvolvimento de habilidades que promovam a autonomia do educando num processo de busca de soluções criativas e colaborativas para respostas aos desafios que lhe surgem.

Alguns autores defendem que para a aprendizagem ocorrer é essencial que o sujeito se envolva ativamente, que veja sentido e funcionalidade no que está sendo ensinado. Nessa concepção o ensino deve ser pautado na contextualização, na problematização e na interdisciplinaridade permitindo ao aluno relacionar diferentes aspectos da sua vida pessoal, social e cultural. 
Para Almeida (1999) uma das formas que proporciona a prática pedagógica interdisciplinar é a metodologia de trabalho por projetos, potencializando a articulação entre os saberes das diversas áreas do conhecimento. Segundo o autor,

[...] o projeto evidencia-se uma atividade que rompe com as barreiras disciplinares, torna permeável as suas fronteiras e caminha em direção a uma postura interdisciplinar para compreender e transformar a realidade em prol da melhoria da qualidade de vida pessoal, grupal e global (ALMEIDA, 1999, p. 2).

Deste modo, o trabalho por projetos exige uma postura colaborativa entre as pessoas envolvidas, criando e fortalecendo laços dentro de um grupo interdisciplinar. Nessa perspectiva, é preciso pensar um processo de ensino que considere as expectativas dos estudantes em relação à construção do seu próprio conhecimento, incorporando a prática interdisciplinar de maneira contínua, posto que a troca de informações e conhecimentos contextualizados já fazem parte do cotidiano dos sujeitos. Mas, será o trabalho por projetos a única forma de promover um ensino e prática interdisciplinar?

As discussões promovidas durante as aulas no curso de Especialização em Ensino de Ciências Naturais e Matemática, ofertado pelo Instituto Federal de Educação, Ciência e Tecnologia do Rio Grande do Norte (IFRN), Campus Currais Novos, sempre com a ênfase da "interdisciplinaridade" como princípio e proposta metodológica, provocaram algumas inquietações sobre o fazer pedagógico em sala de aula, suscitando questionamentos do tipo: Será possível uma prática docente interdisciplinar na sala de aula, conforme a nossa organização curricular se apresenta? Como fazer isso num currículo organizado por disciplinas com tempos determinados para cada aula?

A curiosidade em observar a prática docente interdisciplinar, deu origem a esse trabalho tendo como objetivo reconhecer, em algumas práticas pedagógicas docentes, na sala de aula, a efetivação do princípio da interdisciplinaridade.

Dessa forma, buscou-se identificar as percepções dos docentes em relação ao conceito de Interdisciplinaridade, as dificuldades e/ou facilidades que encontram no desenvolvimento da prática interdisciplinar na sala de aula. Foram feitas observações de aulas envolvendo as disciplinas de Biologia, Química e Física no Ensino Médio Integrado, no IFRN Campus Currais Novos. A escolha da instituição se deu, exatamente por adotar o currículo integrado, que teoricamente, possibilita a integração e interação de conteúdos de forma contextualizada e interdisciplinar.

A metodologia está pautada numa abordagem qualitativa, com foco no estudo de caso, utilizando como técnicas de pesquisa a observação e a entrevista semiestruturada. A fundamentação teórica está referendada pelo pensamento de Fazenda (2011), Morin (2000), Delors (2012), Moraes (2010), dentre outros.

Considerando os objetivos propostos, este trabalho se organiza tendo na primeira seção, alguns conceitos e/ou concepções relacionados ao termo interdisciplinaridade, bem como alguns obstáculos, dificuldades e/ou possibilidades. Nas seções seguintes, apresentam-se, respectivamente, o percurso metodológico, resultados e discussões e, por fim, as considerações finais. 


\section{CONCEPÇÕES SOBRE INTERDISCIPLINARIDADE}

Numa sociedade globalizada, o impacto das novas tecnologias, afeta as atividades relacionadas ao trabalho, à educação e à formação humana de forma geral.

Esse novo tipo de sociedade, caracterizada como sociedade do conhecimento e da informação, fruto de uma revolução científica e tecnológica, vem impondo mudanças de paradigmas educacionais, transformando radicalmente 0 fazer cotidiano escolar, numa perspectiva de um ensino contextualizado, que possa minimizar a fragmentação do saber. Assim sendo, entende-se que, um ensino organizado de forma disciplinar, que privilegia a memorização de fatos e apresenta respostas prontas, não atende as expectativas da sociedade vigente.

Nesse contexto, mudam-se os conceitos de tempo e de espaço escolar e, consequentemente $o$ de ensino e de aprendizagem, gerando diferentes ambientes socioculturais e educativos diversificando as fontes do conhecimento e do saber.

Com a Lei de Diretrizes e Bases da Educação Nacional (LDBEN), no 9.394/96, surge a abertura de um olhar reflexivo sobre as concepções de ensino e de aprendizagem que atendam as expectativas de uma formação humana integral, por meio de uma organização curricular que integre os conteúdos.

O Relatório da Comissão Internacional sobre Educação para o Século XXI, coordenado por Jacques Delors, para a UNESCO, traz a discussão acerca dos quatro pilares da educação, tomando como base os princípios de aprendizagem necessários ao século XXI: o aprender a aprender, o aprender a fazer, o aprender a conviver e o aprender a ser. Segundo Delors (2012), com a circulação, o armazenamento de informações e a comunicação no século XXI, a educação deve organizar-se em torno dessas quatro aprendizagens fundamentais para poder dar resposta ao conjunto das suas missões num contexto de uma sociedade complexa.

As discussões oriundas da necessidade de promover uma integração disciplinar no currículo, torna-se consenso entre docentes e pesquisadores em educação, embora sejam perceptíveis as discrepâncias existentes entre o "dizer" e o "fazer". Assume-se uma concepção de ensino onde a contextualização e a interdisciplinaridade passam a ser vistos como elementos fundamentais a uma prática pedagógica que promova uma aprendizagem significativa, com sentido e funcionalidade.

Desta maneira, destaca-se a importância da interdisciplinaridade como possibilidade de integrar os conteúdos por áreas de conhecimentos, com o propósito de promover uma interação entre os diversos saberes. Na busca de compreender melhor o conceito de interdisciplinaridade, buscou-se em Fazenda (2011), uma breve explicação sobre o significado dos termos integração" e "interação".

Para a autora, a integração está relacionada a um aspecto formal da interdisciplinaridade, ou seja, à questão de organização das disciplinas num 
programa de estudos, confundindo-se com os termos de multi ${ }^{1}$ ou pluridisciplinar ${ }^{2}$, onde não ocorre uma preocupação com a interação.

Por sua vez, a interação está intimamente ligada "a condição de efetivação da interdisciplinaridade, pressupondo uma integração de conhecimentos visando novos questionamentos, novas buscas, enfim, a transformação da própria realidade" (FAZENDA, 2011, p. 12). Observa-se, portanto, no pensamento de Fazenda (2011), que a interação seria condição necessária para a interdisciplinaridade acontecer.

Para Fazenda (2014), a interdisciplinaridade constitui-se numa atitude, uma maneira de ser e fazer relacionada a uma nova forma de enxergar e lidar com o conhecimento. Atitude essa que qualifica o que é comum a duas ou mais disciplinas ou outros ramos do conhecimento. A autora alerta que o aspecto metodológico se faz necessário, mas não se pode fazer dele um fim, pois "interdisciplinaridade não se ensina nem se aprende, apenas vive-se, exerce-se e, por isso, exige uma nova pedagogia, a da comunicação" (FAZENDA, 2011, p. 11).

Por conseguinte, compreende-se Interdisciplinaridade como uma questão de atitude de abertura ao diálogo entre os diversos saberes, por meio da interação numa relação de intersubjetividade, onde todo o conhecimento é igualmente importante, substituindo a fragmentação do saber por uma visão unitária do ser humano.

Nessa linha de pensamento, Morin (2000, p. 39), propõe que "a educação deve promover a 'inteligência geral' apta a referir-se ao complexo, ao contexto, de modo multidimensional e dentro da concepção global". Nesse sentido, o autor referese a compreensão dos princípios do conhecimento pertinente ${ }^{3}$ necessários a educação numa sociedade globalizada, rompendo com um ensino fragmentado, compartimentalizado.

Segundo Luck (1994, p.7) a interdisciplinaridade

[...] não consiste na desvalorização das disciplinas e do conhecimento produzido por elas, ao contrário, possibilita uma maior interação entre as ciências, e assim, faz uma nova abordagem de determinados conteúdos, promovendo um maior dinamismo no processo de ensino e de aprendizagem.

Nessa perspectiva, a autora destaca a possibilidade da integração e interação entre diferentes disciplinas curriculares, destacando a importância de se trabalhar os conteúdos de forma integradora, potencializando o processo de ensino

\footnotetext{
${ }^{1}$ Multidisciplinar compreende justaposição de disciplinas diversas, desprovidas de relação aparente entre elas.

${ }^{2}$ Pluridisciplinar refere-se a justaposição de disciplinas, mais ou menos, vizinhas nos domínios do conhecimento.

${ }^{3} \mathrm{O}$ contexto (para que as informações tenham sentido, é preciso situá-las num contexto); o global (significa estabelecer as relações entre o todo e as partes, indo além do contexto); o multidimensional (considera o sujeito e suas dimensões: biológica, psíquica, social, afetiva e racional; e a sociedade compreende as dimensões histórica, econômica, sociológica, religiosa...) e o complexo (significa a união entre a unidade e a multiplicidade).
} 
e de aprendizagem, numa perspectiva sociointeracionista, considerando a premissa de que aprendizagem e desenvolvimento são produtos da interação social. compreende

No entendimento de Teixeira (2016, p. 27), a interdisciplinaridade

[...] a interação de duas ou mais disciplinas. Essas interações podem implicar transferências de leis de uma disciplina a outra, originando, em alguns casos, um novo corpo disciplinar, como, por exemplo, a bioquímica ou psicolinguística, portanto, é um sistema suscetível de fazer com que duas ou mais disciplinas interajam entre si. Esta interação pode ir da simples comunicação das ideais até a integração mútua dos conceitos, da epistemologia, da terminologia, dentre outras.

Diante do exposto, questiona-se sobre as possibilidades e dificuldade para a efetivação de uma prática interdisciplinar, num contexto onde o currículo ainda é organizado de forma disciplinar e o ensino, nessa perspectiva interdisciplinar, propõe uma prática dialógica, problematizadora e investigativa.

Para Fazenda (2011) alguns obstáculos dificultam uma prática interdisciplinar, categorizando-os como: obstáculos epistemológicos e instrucionais, obstáculos psicossociológicos e culturais, obstáculos metodológicos, obstáculos quanto à formação e quanto aos materiais. Dentre os obstáculos enumerados, a autora destaca os metodológicos como de maior importância, considerando que,

[...] a elaboração e adoção de uma metodologia de trabalho interdisciplinar implica a prévia superação dos obstáculos institucionais, epistemológicos, psicossociológicos, culturais, de formação de pessoal capacitado e também a superação dos obstáculos materiais. [...] como atitude, torna-se necessário que ao elaborar essa metodologia cada um esteja impregnado de um espírito epistemológico suficientemente amplo, para que possa observar as relações de sua disciplina com as demais, sem negligenciar o terreno de sua especialidade (FAZENDA, 2011, p. 92).

Por conseguinte, pode-se entender que é possível mergulhar, nos mais variados campos da percepção relacionados à interdisciplinaridade que estão presentes em todas as nossas ações realizadas diariamente, quer pedagógicas ou não. Ações essas que por muitas vezes, passam despercebidas em várias situações que são vivenciadas diariamente tanto no contexto acadêmico quanto extraescolar.

\subsection{INTERDISCIPLINARIDADE E CURRÍCULO ESCOLAR}

No contexto atual, como organizar um currículo que atenda às necessidades de aprendizagem numa sociedade complexa, que exige um novo olhar teóricometodológico frente as incertezas do conhecimento?

Segundo Moraes (2010, p. 293), 
A palavra currículo vem do latim Curriculum que significa pista de corrida, caminho, percurso, trajetória. Palavra que indica também travessia, com seus pontos de partida e de chegada. Um caminho a ser seguido, realimentado, reorientado e bifurcado sempre que necessário pela ação dos envolvidos no cenário educacional. Mas, um caminho que, a princípio, deveria estar sujeito ao imprevisto, ao inesperado; sujeito às situações emergentes, ao acaso, à ecologia da ação, o que na maioria das vezes não acontece.

Entende-se o currículo como um documento que traduz a identidade política e pedagógica da escola, revelando os caminhos teóricos e metodológicos, com metas e objetivos determinados, tomando como base a concepção de sujeito, de sociedade e de mundo, numa perspectiva de contexto social, político, econômico. Compreende-se currículo como algo permanente, que envolve o cotidiano da comunidade escolar num processo de construção, desenvolvimento e aprimoramento de ações que se entrelaçam pelas suas próprias naturezas de coletividade e integração entre si.

As Diretrizes Curriculares Nacionais para o Ensino Médio (DCNEM, 2013) orientam um currículo organizado por áreas de conhecimento ${ }^{4}$, com tratamento metodológico evidenciando a contextualização e a interdisciplinaridade, como forma de assegurar a transversalidade e a articulação do conhecimento de diferentes componentes curriculares entre os saberes das diferentes áreas de conhecimento.

Nessa perspectiva, a interdisciplinaridade é entendida como uma abordagem teórico-metodológica com ênfase no trabalho de integração das diferentes áreas do conhecimento, aberto ao diálogo e ao planejamento de forma cooperativa, assumindo o princípio de que:

[...] "todo conhecimento mantém um diálogo permanente com outros conhecimentos", e que "o ensino deve ir além da descrição e constituir nos estudantes a capacidade de analisar, explicar, prever e intervir, objetivos que são mais facilmente alcançáveis se as disciplinas, integradas em áreas de conhecimento, puderem contribuir cada uma com sua especificidade, para o estudo comum de problemas concretos, ou para o desenvolvimento de projetos de investigação e/ou de ação" (BRASIL, 2013, p. 28).

Percebe-se que o termo "interdisciplinaridade" aparece com frequência nos discursos acadêmicos e como fazeres pedagógicos cotidianos, talvez por estar posto na legislação educacional como princípio metodológico e, consequentemente, nas propostas curriculares das escolas.

Numa linha de pensamento metodológico e transversal, no sentido do desenvolvimento de um trabalho pedagógico integrado entre toda a comunidade escolar, Luck (1990), defende a interdisciplinaridade como processo que envolve a integração e engajamento docente, num trabalho colaborativo, de interação das disciplinas do currículo escolar entre si e com a realidade, de modo a superar a fragmentação do ensino, objetivando a formação integral dos alunos.

\footnotetext{
${ }^{4}$ As áreas indicadas são: Linguagens, Códigos e suas Tecnologias; Ciências da Natureza, Matemática e suas Tecnologias e Ciências Humanas e suas Tecnologias.
} 
Nessa direção, a integração se faz essencialmente no nível de associação dos conhecimentos singulares, tendo em vista um conhecimento universal, que agregue saberes em rede e articulados com situações e experiências de vida de maneira coletiva refletindo numa troca e complementaridade de aprendizagens recíprocas entre professores e alunos. Nesse sentido, compreende-se que uma integração.

[...] requer atributos de ordem externa, melhor dizendo da ordem das condições existentes e possíveis, diferindo de uma integração interna ou interação, da ordem das finalidades e sobretudo entre as pessoas. Com isso retomamos novamente a necessidade de condições humanas diferenciadas no processo de interação que faça que saberes de professores numa harmonia desejada se integrem aos saberes dos alunos, melhor dizendo, dos Direitos Humanos. Isso requer um outro tipo de profissional com novas características, ainda sendo pesquisadas (FAZENDA, 2011, p. 154-155).

No contexto deste trabalho, se faz necessário destacar a concepção de Currículo Integrado defendido no Projeto Político Pedagógico (PPP) do Instituto Federal de Educação, Ciência e Tecnologia do Rio Grande do Norte (IFRN).

O Currículo Integrado é compreendido como um modelo fundamentado na globalização das aprendizagens e na interdisciplinaridade, por meio do diálogo entre os diversos saberes e as experiências socioculturais numa compreensão crítica e reflexiva da realidade. Nesse sentido, o conhecimento é organizado de modo que os conceitos sejam vistos como sistemas de relações de uma totalidade concreta, com o objetivo de explicá-la e compreendê-la, estabelecendo relações entre conhecimentos gerais e específicos ao longo de todo o processo de formação do sujeito.

Nessa direção, o PPP do IFRN assume o currículo como:

[...] um conjunto integrado e articulado de atividades intencionadas, pedagogicamente concebidas a partir da visão crítica de ser humano, de mundo, de sociedade, de trabalho, de cultura e de educação, organizadas para promover a construção, a reconstrução, a socialização e a difusão do conhecimento. Essas atividades intencionadas, sob sustentação de um aporte histórico-crítico, visam à formação integral dos educandos, objetivando, também, torná-los cidadãos aptos a contribuir com o desenvolvimento socioeconômico local, regional, nacional e global, na perspectiva da edificação de uma sociedade democrática e solidária (IFRN, 2012, p. 49).

Observa-se que o currículo do IFRN, está fundamentado em bases filosóficas, epistemológicas, metodológicas, socioculturais e legais, a partir de uma concepção de sociedade, de trabalho, de cultura, de educação, de ciência e de tecnologia, e de ser humano. Destacam-se como princípios orientadores da prática pedagógica no IFRN: a pesquisa como princípio pedagógico, o trabalho como princípio educativo, o respeito à diversidade e a interdisciplinaridade. Compreende a interdisciplinaridade como um princípio basilar que, 
[...] visa estabelecer elos de complementaridade, de convergência, de interconexões, de aproximações e de intersecção entre saberes de diferentes áreas. Do ponto de vista da materialização na prática, implica uma organização curricular e didático-pedagógica pautada na integração e na contextualização de conhecimentos. A interdisciplinaridade utiliza-se de estratégias de ensino e aprendizagem que possibilitam, ao mesmo tempo, um diálogo com as bases científicas, com a vida em sociedade, com a atividade produtiva e com as experiências subjetivas, favorecendo, aos alunos, uma formação integral (IFRN, 2012, p. 67).

Nesse sentido, é importante reconhecer que uma formação escolar contínua com base em concepções interdisciplinares pode ser mais humanizada, valorizando muito mais o indivíduo, suas vivências, suas relações, etc. Sendo assim, é relevante enfatizar que um currículo integrado tem muito a cooperar no desenvolvimento pessoal e profissional de docentes e estudantes, possibilitando, de fato, uma formação humana integral.

\subsection{INTERDISCIPLINARIDADE E A FORMAÇÃO DOCENTE}

Uma das propostas apresentadas pelos Parâmetros Curriculares Nacionais (1999) traz a interdisciplinaridade como forma de desenvolver um trabalho de integração dos conteúdos de uma disciplina com outras áreas de conhecimento, como também contribuir com o aprendizado do aluno. Porém, estudos têm revelado que a interdisciplinaridade ainda é pouco trabalhada em sala de aula, quando muitos docentes não se sentem preparados para trabalhar com essa metodologia em sala de aula.

Segundo Meinardi (1999, p.28), a maioria de nós, nos formamos como docentes de uma disciplina, trabalhamos sozinhos em sala de aula e não temos tempo remunerado para discutir com docentes de outras disciplinas.

A formação docente ainda foca em um ensino direcionado as especificidades da área, não proporcionando um olhar na totalidade do saber. Ou seja, muitos foram formados para pensar de forma individual e não olhar a sua área de conhecimento como parte de um todo, que ela em conjunto com as demais áreas forma algo indispensável à vida, ou seja, os vários conhecimentos produzidos por elas são utilizados para se chegar a um único produto.

Como explica Tardif (2007) o saber docente é um saber plural, formado pelo amálgama, mais ou menos coerente, de saberes oriundos da formação profissional e de saberes disciplinares, curriculares e experienciais. Assim, não basta apenas saber a sua própria disciplina e, sim que o professor esteja perfeitamente em sintonia com os demais tipos de conhecimentos ao seu redor, o que demonstra não ser tarefa fácil.

Essa temática é compreendida como uma forma de trabalhar em sala de aula, no qual se propõe um tema com abordagens em diferentes disciplinas. É compreender, entender as partes de ligação entre as diferentes áreas de conhecimento, unindo-se para transpor algo inovador, resgatar possibilidades e 
ultrapassar o pensar fragmentado. É a busca constante de investigação, na tentativa de superação do saber (JAPIASSU, 1976).

Para que os profissionais da educação, em particular os docentes, consigam romper com um ensino fragmentado, é preciso que estejam em contínua formação para desempenhar o seu papel no processo de ensino e de aprendizagem de maneira articulada com a realidade de vida do alunado, proporcionando uma aprendizagem e aprimoramento dos conhecimentos mais concretos e com maior significado no contexto social no qual os alunos estão inseridos. Nessa direção, corrobora-se com o pensamento de Fazenda (2011, p. 84) quando destaca que:

[...] O valor e a aplicabilidade da Interdisciplinaridade, portanto, podem-se verificar tanto na formação geral, profissional, de pesquisadores, como meio de superar a dicotomia ensino pesquisa e como forma de permitir uma educação permanente.

Compreende-se que a interdisciplinaridade não dilui as disciplinas, mas, integra as disciplinas a partir da compreensão das múltiplas causas ou fatores que intervêm sobre a realidade e trabalha todas as linguagens necessárias para a constituição de conhecimentos, comunicação e negociação de significados e registro sistemático dos resultados (BRASIL, 1999).

Nessa perspectiva, destaca-se que uma boa formação docente está direcionada para a capacidade de reflexão e das ações do docente, na qual os seus conhecimentos experienciais, disciplinares e cotidianos sejam projetados e contextualizados e com habilidade de podê-los transmitir em conjunto aos seus alunos. Nesse sentido, Nóvoa (1995) defende que a formação não se constrói por acumulação (de cursos, de conhecimentos ou de técnicas), mas sim, através de um trabalho de reflexividade crítica sobre as práticas e de (re)construção permanente de uma identidade pessoal. Por isso é tão importante investir a pessoa e dar um estatuto ao saber da experiência (NÓVOA, 1995, p. 25).

Considerando os pressupostos da interdisciplinaridade como atitude, faz-se necessário oferecer ao professor, em sua formação inicial, subsídios teóricos interdicisplinaridades, como possibilidades de atuação na prática, objetivando um ensino que transforme. É cabível que os cursos de licenciaturas trabalhem e conheçam propostas e objetivando práticas interdisciplinares, formando professores críticos e inovadores que possibilitem o diálogo entre suas ideias e dos alunos, resultando assim uma melhor qualidade no ensino, pois a necessidade de práticas pedagógicas interdisciplinares impõe-se, não só como forma de compreender e modificar o mundo, como também por uma exigência interna das ciências, que buscam o restabelecimento da unidade perdida do saber.

Diante de todo o exposto nesta obra acadêmica, como educadores, nos sobrevém, a seguinte indagação: como desenvolver uma prática pedagógica interdisciplinar contínua em todo o processo de ensino e de aprendizagem?

Percebe-se que trabalhar por meio de projetos pedagógicos interdisciplinares, embora exijam várias habilidades e competências do professor, a continuidade da prática e a reflexão sobre a mesma, viabilizam muitos benefícios a ele e aos alunos, por que cria condições para o estudante mostrar os saberes 
prévios que possui sobre o assunto investigado; dar-lhe oportunidade de se mobilizar na busca e na construção de conhecimentos novos; exercita a desenvoltura, a sociabilidade, a criatividade dentre outras competências; utiliza o método científico, que permite a formação do espírito científico; desenvolve a autoestima do aluno e a confiança em si mesmo.

Sendo assim, o ponto de partida para implementação de uma pedagogia por meio de projetos interdisciplinares é o professor perceber a necessidade de mudanças de atitudes, de paradigma didático-pedagógico e, corajosamente renovarse. Isso implica optar por "reaprender a ser professor". Acostumar-se, em suas atividades, a procurar ver mais longe, a estar atento às mudanças que o mundo de amanhã exigirá dos nossos alunos".

Portanto, o professor precisa exercitar a prática pedagógica interdisciplinar por meio de projetos pedagógicos, favorecendo um ensino pautado no desenvolvimento da capacidade investigativa, reflexiva e crítica, aplicando os conhecimentos obtidos no processo de formação no exercício da prática docente, propiciando o entendimento da relação teoria-prática como um processo indissociável, no exercício da prática docente.

Como também, o desenvolvimento de uma prática pedagógica articulada com os saberes construídos cientificamente. Sendo assim, como educadores precisamos estar preparados, assim como continuar aprimorando os conhecimentos, métodos e técnicas didáticas para desenvolver novas práticas pedagógicas contextualizadas e integradoras do conhecimento, como também, manter sempre o interesse em novas metodologias, estarmos sempre atualizados e buscarmos a nossa própria superação, para que dessa forma possa oferecer e desenvolver um trabalho pedagógico mais concreto, significativo e interessante, diante das transformações sociais e interesses dos nossos alunos que acompanham as evoluções de uma vida social tão competitiva e inovadora

\title{
3 CAMINHOS METODOLÓGICOS
}

Os caminhos percorridos para a efetivação da pesquisa, se configuram numa abordagem qualitativa, caracterizando-se como estudo de caso.

De acordo com Ramoginino (1982 apud MINAYO; SANCHES, 1983, p.246), o trabalho qualitativo compreende,

\begin{abstract}
Um trabalho de conhecimento social que tem que atingir três dimensões: a simbólica, a histórica e a concreta. A dimensão simbólica contempla os significados dos sujeitos; a histórica privilegia o tempo consolidado do espaço real e analítico; e a concreta refere-se às estruturas e aos atores sociais em relação.
\end{abstract}

Observa-se que essas dimensões relacionam-se com a pesquisa na medida em que, os três requisitos citados pelo autor contemplam o caráter qualitativo, pois, ao incluir os indivíduos e seu espaço social, essas características que norteiam o tipo de pesquisa qualitativa, a fim de que possa depreender seus fenômenos, 
causalidades, de modo que a partir dessa compreensão possa surgir a reflexão mediante o estudo, que será permeado pela observação e participação ao longo do seu desenvolvimento. Além do mais, neste tipo de pesquisa a interpretação dos fenômenos e a atribuição de significados são a verdadeira base, sendo que o uso de ferramentas estatísticas não se faz necessário. Como Silva e Menezes (2005) descrevem, o ambiente natural é a fonte da coleta de dados e o pesquisador é o instrumento- chave.

Para Ludke e André (2017), o estudo de caso é sempre bem delimitado, devendo ser claramente definido no desenrolar do trabalho. A autora defende que como estudo qualitativo, "[...] é o que se desenvolve numa situação natural, é rico em dados descritivos, tem um plano aberto e flexível e focaliza a realidade de forma complexa e contextualizada (LUDKE; ANDRÉ, 2017, p. 21).

Nessa perspectiva, como procedimento metodológico para a coleta de dados, foram utilizadas as técnicas da observação de aulas e da entrevista semiestruturada (ANEXO 1) com os docentes participantes da pesquisa. Foi elaborado um roteiro para direcionamento da observação das aulas (ANEXO 2). As entrevistas com os docentes foram gravadas em áudios e transcritas posteriormente, possibilitando uma análise mais acurada dos dados.

Os sujeitos participantes da pesquisa são docentes efetivos do IFRN Campus Currais Novos que lecionam as disciplinas que compreendem o Ensino de Ciências Naturais, nos cursos Técnicos de Ensino Médio Integrado.

Conforme mencionado na introdução deste trabalho, a escolha da instituição se deu, pelo fato da mesma adotar o currículo integrado como forma de organização curricular, considerando dentre os princípios de orientação da prática pedagógica, a contextualização e a interdisciplinaridade.

Em relação a escolha das disciplinas de Química, Física e Biologia, foi devido ao fato do curso de especialização está focado no Ensino de Ciências Naturais e da Matemática, numa perspectiva interdisciplinar, propondo uma atuação docente de forma inter ou transdisciplinar em práticas que provoquem a transversalidade da ética e da cidadania no ensino dessas ciências.

Logo que as estratégias metodológicas da pesquisa foram definidas, os sujeitos participantes da pesquisa foram contactados, para demonstrarem aceitação ou não, em participar da pesquisa.

No quadro demonstrativo a seguir (Quadro 01), apresenta-se a caracterização dos sujeitos participantes, sendo designados como P1, P2 e P3, respectivamente. 


\section{Quadro 01 - Caracterização dos professores entrevistados.}

\begin{tabular}{|c|c|c|c|c|c|}
\hline Professor & Idade & $\begin{array}{l}\text { Disciplina } \\
\text { que Leciona }\end{array}$ & $\begin{array}{l}\text { Nível de ensino } \\
\text { que atua }\end{array}$ & Formação acadêmica & $\begin{array}{l}\text { Tempo de } \\
\text { atuação }\end{array}$ \\
\hline P1 & $\begin{array}{c}26 \\
\text { anos }\end{array}$ & Física & $\begin{array}{l}\text { Ensino Médio } \\
\text { Ensino Superior }\end{array}$ & $\begin{array}{l}\text { Licenciado em Física/UFRN; } \\
\text { Mestre na área do Ensino de } \\
\text { Ciências Naturais e } \\
\text { Matemática/UFRN }\end{array}$ & 03 anos \\
\hline P2 & $\begin{array}{c}30 \\
\text { anos }\end{array}$ & Biologia & $\begin{array}{l}\text { Ensino Médio } \\
\text { Ensino Superior }\end{array}$ & $\begin{array}{l}\text { Licenciada em Ciências } \\
\text { Biológicas; Mestra em Psicologia. }\end{array}$ & 03 anos \\
\hline P3 & $\begin{array}{c}31 \\
\text { anos }\end{array}$ & Química & $\begin{array}{l}\text { Ensino Médio } \\
\text { Ensino Superior }\end{array}$ & $\begin{array}{l}\text { Licenciado em Química/UFRN; } \\
\text { Doutor em Química Teórica/UFRN }\end{array}$ & $\begin{array}{l}02 \text { anos e } \\
\text { meio }\end{array}$ \\
\hline
\end{tabular}

Fonte: Elaborada pela autora

Os dados obtidos nessa caracterização apontam para um grupo docente jovem, considerando a faixa etária entre 26 e 31 anos de idade, bem como o tempo de atuação em sala de aula. Apesar da característica jovial, apresentam uma formação acadêmica como mestres e doutores o que demonstra uma formação de alto nível, com capacitação de atuar com qualidade no contexto educacional atual.

Por fim, foram analisados os áudios das entrevistas, como também os pontos destacados nas observações das aulas, enriquecendo a escrita do trabalho, na tentativa de encontrar indícios de possibilidades de uma prática interdisciplinar na sala de aula.

\section{AFINAL, É POSSÍVEL UMA PRÁTICA DOCENTE INTERDISCIPLINAR NA SALA DE AULA?}

Durante o período de 30 de abril a 08 de maio do corrente ano, foi possível realizar a observação das aulas nas disciplinas propostas como obtenção de dados da pesquisa.

$\mathrm{Na}$ aula desenvolvida por P1, estavam presentes 32 estudantes na sala de aula. Era a aula da disciplina de Física no Curso Técnico de Nível Médio Integrado em Manutenção e Suporte em Informática, a qual começou pontualmente, às 8h50min. O docente começou o seu trabalho revisando o conteúdo que foi ministrado na aula anterior, por meio de slides, com a duração de 25 minutos. No percurso dessa revisão, observou-se o envolvimento dos estudantes com 0 professor e com o conhecimento proposto, onde as perguntas e respostas confundiam-se simultaneamente, de forma bem interativa. No que se refere ao conteúdo trabalhado percebia-se as relações possíveis com conteúdo específico da Geografia e da Química. Dando continuidade a aula, o professor entrou com o 
conteúdo sobre "Espectrômetro de massa", estabelecendo relações com conteúdos de Química e com conteúdos relacionados com a disciplina Controle e Estatística de Qualidade, específica do Curso Técnico de Nível Médio em Alimentos.

A aula desenvolvida por P2, era da disciplina de Biologia, a qual começou pontualmente, às $7 \mathrm{~h}$. Teve início com a chamada dos alunos e, logo em seguida deu-se continuidade ao assunto da aula anterior, referente a Ecologia e a distribuição da vida. Notava-se o princípio da interdisciplinaridade tomando conta da aula, pois, o conteúdo foi relacionado com a Geografia, envolvendo questões ligadas a caatinga, ao ecossistema/temperatura, aos rios voadores e as altitudes. Vale ressaltar a participação e atenção dos estudantes durante o percurso da aula, sempre relacionando as questões com o cotidiano dos mesmos. A aula finalizou às 8h30min.

A aula desenvolvida por P3 apresentou características diferentes das demais, pois foi uma aula da disciplina de Química, ministrada pelo professor e pela técnica de laboratório, no Laboratório de Química, com a turma do $2^{\circ}$ ano do Curso Técnico de Nível Médio Integrado em Informática. O tema da aula abordava "soluções químicas". Desde o início da aula, às 8h50min, era notório a ansiedade dos estudantes pelas explicações, bem como pelo manuseio das vidrarias. Percebiase que o conteúdo trabalhado necessitava, automaticamente, de conteúdos específicos de outras áreas do conhecimento, como a Matemática, por exemplo, para fazer os cálculos químicos necessários, para melhor compreensão. A matemática foi à disciplina mais presente nessa aula. Vale salientar que a aula foi bem contextualizada com o cotidiano do aluno, tornando-se uma aula prazerosa e motivadora. Ou seja, a interdisciplinaridade estava sendo trabalhada mesmo sem o docente perceber.

Durante as aulas, foi possível observar uma postura docente onde a interdisciplinaridade aparece de forma natural e intencional, corroborando com Fazenda (2011), quando ela defende que a interdisciplinaridade depende basicamente da atitude que promove a interação e colaboração entre as diversas disciplinas e conteúdos específicos.

Em se tratando do Ensino Médio, Carlos (2007), aponta que a interdisciplinaridade se torna natural diante do conhecimento, sem fragmentação e sem isolamento e que o conhecimento abordado de maneira interdisciplinar favorece o aprendizado do aluno, e consequentemente mobiliza o interesse dos mesmo.

Nessa mesma linha de pensamento, Oliveira (2010) defende a utilização da interdisciplinaridade como forma de desenvolver um trabalho de integração dos conteúdos de uma disciplina com outras áreas de conhecimento contribuindo para o aprendizado do aluno.

Sendo assim, entende-se que a interdisciplinaridade visa superar a fragmentação entre as disciplinas, fazendo com que estas dialoguem a fim de encontrar e construir as respostas e os conhecimentos relevantes para aluno.

Após a observação da aula, foi feita a entrevista semiestruturada com cada professor, cujos resultados serão expostos e analisados.

Quando questionados sobre o que é interdisciplinaridade, como eles compreendem essa concepção, os entrevistados dispuseram as seguintes respostas: 


\begin{abstract}
P1: [...] essa pergunta é bem pertinente para o ensino das Ciências, mas que gera uma controvérsia porque para muitos a interdisciplinaridade é o simples envolvimento de várias disciplinas de uma mesma prática pedagógica. Mas, que na verdade essa simples participação de várias disciplinas caracteriza a multidisciplinaridade. Para que haja de fato a interdisciplinaridade têm que haver um envolvimento entre essas várias disciplinas de modo que haja uma conexão maior entre as diferentes áreas que compõem cada uma dessas disciplinas de modo que não se consiga distinguir com facilidade de uma mesma prática pedagógica onde começa uma disciplina e onde inicia a outra.
\end{abstract}

P2: [...] é quando as ciências se conversam de forma que não se consegue ver os limites. Por exemplo, muitos pensam que a interdisciplinaridade é basicamente pegar um tema gerador e desse tema cada um vai trabalhar com ele em sua aula. E para mim não é bem assim... a interdisciplinaridade é uma "coisa" que se consegue mesclar os conteúdos sem separá-los.

P3: [...] é mostrar que o conteúdo que leciona tem uma relação com outras disciplinas, basicamente de uma forma bem objetiva, é mostrar a relação entre a química com as outras na área da ciência.

Analisando as respostas de cada docente é importante destacar que cada profissional trabalha a interdisciplinaridade da forma como a entende ou que lhe convém ou, ainda, que julga ser a mais adequada em suas aulas. Nesse sentido, corrobora-se com Fazenda (2003) quando diz que a interdisciplinaridade:

[...] se revela mais como processo que produto, ou seja, corresponde ao ato de construir pontes entre as diferentes disciplinas, permitindo que 0 conhecimento produzido ultrapasse os limites disciplinares e destaca a compreensão da interdisciplinaridade numa categoria de ação, diferenciando-a das disciplinas, que estariam na categoria de conhecimento (FAZENDA, 2003).

É notório que os três entrevistados tem um olhar particular a respeito de conceituar a interdisciplinaridade, o primeiro entrevistado pontua que para que haja de fato essa ferramenta têm que haver um envolvimento entre várias disciplinas de modo que haja uma conexão maior entre as diferentes áreas que compõem cada uma delas, de modo que não se consiga distinguir com facilidade de uma mesma prática pedagógica onde começa uma disciplina e onde inicia a outra. O segundo entrevistado relata que é quando as ciências se conversam de forma que não se consegue ver os limites. Já para o terceiro interrogado o conceito de interdisciplinaridade para ele é mostrar que o conteúdo que ele leciona tem uma relação com outras disciplinas, basicamente de uma forma bem objetiva e mostrar a relação entre a química com as outras na área da ciência.

Dessa maneira, é importante a opinião de todos e remete a reflexão de como cada profissional da educação ver e analisa a interdisciplinaridade. Visto que é um tema bastante polêmico e pouco trabalhado nas graduações. O que de fato foi relatado no desenvolver do trabalho pelos próprios entrevistados.

A segunda pergunta buscou saber se os docentes consideram que teve uma formação interdisciplinar em algum momento de sua formação acadêmica. Os três 
entrevistados afirmaram não ter tido essa formação na sua graduação, conforme observa-se no realto a seguir.

P1: relatou que não teve essa preparação, que a formação dele foi bastante isolada sem que houvesse algum envolvimento entre as disciplinas nas práticas pedagógicas. Vale ressaltar que o mesmo acredita que até hoje esse isolamento acontece nas formações acadêmicas (graduação). Porém, o mesmo relembra que na sua pós (mestrado em ensino de Ciências) teve uma disciplina que instigou uma discussão entre interdisciplinaridade, multidisciplinaridade e transdisciplinaridade. No entanto, ele acredita que foi um momento pontual para uma discussão que cada vez é mais frequente e bastante cobrada dos profissionais da educação.

P2: falou que nem como graduada e nem como mestranda essa formação (ensino interdisciplinar) foi contemplada para sua constituição. Como também, relatou que não se lembra de algum momento, algum professor ter tentado fazer um ensino interdisciplinar.

P3: o mesmo acredita que teve uma concepção interdisciplinar em Química Inorgânica II, em que o professor soube mostrar como ela está relacionada com as áreas da Química, como também a Física e Biologia.

É notório na fala docente a lacuna que existe na formação acadêmica dos professores a respeito da interdisciplinaridade. Lacuna essa que deixa o profissional despreparado para trabalhar e enfrentar seu dia a dia na sala de aula. Essa observação contraria o objetivo das Diretrizes para a Formação Inicial de Professores, quando diz que ela deve propiciar ao professor a capacidade de "compreender o papel do recorte específico da sua disciplina na área de organização curricular em que se insere", bem como na elaboração e execução de projetos e atividades interdisciplinares (SCHÖN, 2000).

Questionados se o trabalho de forma interdisciplinar em sala de aula ajuda no processo de ensino e aprendizagem, os sujeitos responderam que sim, conforme ilustração a seguir.

P1: [...] julga de extrema importância porque quebra o paradigma de que cada matéria é isolada das outras ... é impossível enxergar a Física como sendo uma área isolada de outra área, ... a Química e Matemática tem uma conexão muito forte com a Física... é importante que os alunos percebam esse grau de envolvimentos entre as ciências naturais e humanas.

P2: [...] tento fazer um link entre as disciplinas, porém, existem conteúdos que tem uma facilidade maior, por exemplo, bioquímica. Mas, sempre tento fazer a relação com Química e Física.

P3: [...] sim, acho muito interessante mostrar essa outra abordagem que se pode fazer de um determinado conteúdo para deixar claro para o aluno que não estamos ensinando algo tão focado para um só objetivo, mostrar o conteúdo de forma ampla com outras áreas.

Por último, perguntou se os mesmos buscam trabalhar em sala de aula com a interdisciplinaridade e se ajuda no processo de ensino e aprendizagem. 


\begin{abstract}
P1: tenta na medida do possível já que não teve uma preparação adequada para trabalhar em sala de aula, ele ainda percebe a dificuldade que os docentes têm de interagirem para trabalharem em conjunto em busca da interdisciplinaridade. Porém, o mesmo relata que a interdisciplinaridade se torna mais fácil de trabalhar quando é inserida em projetos, por exemplo, projetos integradores e projetos de pesquisas. Mas, deixando sempre bem claro que é uma prática bem pontual, que os docentes ainda não têm a cultura de trabalhar interdisciplinarmente em sala de aula.
\end{abstract}

P2: Foi relatado que ajudava sim, por que tem alguns conceitos e noções que precisam de outra base, por exemplo, a água é um modelador de temperatura para explicá-la melhor precisa-se dos conceitos de calor específico e de energia para poder explicar melhor esse conteúdo.

P3: A opinião do entrevistado foi bem clara, pois, foi confirmado que ajuda demais, ele relatou de uma aula que foi ministrada por ele, que depois conversando com um colega de biologia, esse colega declara que o tema abordado em sala de aula gerou um questionamento em sua aula. Isso fez com eles trabalhassem duas semanas após com um único tema cada um envolvendo sua área. As aulas foram bem participativas pelos alunos.

Diante do que foi analisado, nota-se que cada um dos entrevistados tem sua opinião a respeito da interdisciplinaridade, como também a busca por trabalhar com ela em sala de aula. Portanto, é fundamental o professor ter profundo conhecimento sobre sua disciplina, sobre os conceitos, conteúdos e métodos próprios do seu campo de conhecimento, para poder dialogar com os outros colegas de outras disciplinas (BITTENCOURT, 2004, p. 256.).

É de grande relevância destacar que o curso de Ciências Naturais e Matemática, acabou levando-os a serem profissionais pesquisadores, ou seja, buscar estudar a interdisciplinaridade e como se pode trabalhar com ela em sala de aula.

Portanto, o tema pesquisado e discutido nessa obra acadêmica, ou seja, a interdisciplinaridade permite refletir não apenas sobre o seu significado literal e sobre as leituras e interpretações dos próprios entrevistados envolvidos, como também, sobre as inter-relações existentes entre as mais variadas áreas do conhecimento, de modo que podemos observar claramente o contexto de aplicação, desenvolvimento e sistematização dos conteúdos trabalhados de maneira articulada, na qual, não se delimite território específico de atuação de certa disciplina.

Ou seja, precisa-se notar que todas as disciplinas dialogam e complementamse entre si, de maneira simultânea e harmoniosa entre quaisquer conteúdos trabalhados. Sendo assim, é importante relatar que os professores precisam sair da nossa zona de conforto limitada a disciplina que foram licenciados e procurar ampliar conhecimentos articulados com as outras áreas do conhecimento, para que possam então, aplicar e desenvolver um ensino-aprendizagem de maneira realmente interdisciplinar e que atenda as expectativas do alunado, tornando o ensino mais concreto e mais significativo no contexto do processo de desenvolvimento da vida escolar quanto extraescolar, tornando os alunos em cidadãos atuantes e influentes na sociedade na qual estão inseridos.

Porém vale salientar que apesar da interdisciplinaridade não está presente na formação dos entrevistados, os mesmos buscam trabalhar em sala de aula, pois acham que a mesma ajuda no processo de ensino e aprendizado. 
Portanto, é plausível a inserção da interdisciplinaridade na vida acadêmica, pois como já foi afirmado nesse trabalho, que a mesma conduz a estudar um tema em que é possível serem trabalhadas diversas disciplinas e possibilita seu amadurecimento tanto na teoria quanto no esclarecer dos fatos na prática. Contudo, são necessárias maiores discussões sobre o tema a fim de estabelecer uma metodologia concreta para o desenvolvimento do trabalho como também o auxílio constante e presente do corpo docente para a realização da mesma.

\section{CONSIDERAÇÕES FINAIS}

Ao longo desse trabalho, buscou-se reconhecer como as práticas interdisciplinares são desenvolvidas no instituto IFRN - Campus Currais Novos e quais as percepções dos docentes sobre o desenvolvimento delas.

Pelo exposto, foi observado que não é simples procurar definições "finais" para a interdisciplinaridade, não seria algo propriamente interdisciplinar, mas sim, na verdade, disciplinar; na medida em que não existe uma definição única possível para este conceito. Assim sendo, a reflexão sobre 0 conceito do termo interdisciplinaridade é muito mais abrangente do que entendimentos pessoais de profissionais educacionais e práticas pedagógicas desenvolvidas em salas de aulas ou instituições escolares.

Durante todo o desenvolvimento deste trabalho acadêmico, pode-se observar que os docentes são capazes de trabalhar com a interdisciplinaridade em sala de aula, e que muitas práticas interdisciplinares são desenvolvidas no ambiente escolar sem o professor perceber.

Além do mais, com relação a essa temática didática já citada, muitos educadores pensam que a mesma só pode ser desenvolvida em projetos com a interação de vários profissionais da educação, entretanto, pode ser trabalhada na aula de cada professor. Dessa maneira, é importante destacar que durante o desenvolvimento dessa pesquisa percebe-se que a interdisciplinaridade parte também da busca reflexiva e de ações do professor, pois, ao relacionar várias disciplinas na busca do aprendizado facilita o aprendizado, como também estimula o interesse do aluno pelo conteúdo trabalho.

No entanto, é preciso perceber também que a interdisciplinaridade é um mecanismo intrínseco da construção e aprimoração do conhecimento. Dessa forma, os profissionais da educação, em especial os educadores, precisam estar sempre se auto avaliando no que diz respeito a sua prática de ensino-aprendizagem, verificando se realmente estão desenvolvendo um trabalho educativo perante seus alunos de maneira articulada com as diversas áreas do conhecimento de modo contínuo.

Pensar em interdisciplinaridade envolve inúmeros fatores pessoais e profissionais incumbidos aos educadores compromissados e vocacionados com a maravilhosa arte da educação. Pois, para que um professor consiga de fato desenvolver um trabalho interdisciplinar, não basta apenas dominar o conteúdo da disciplina que leciona e entender a grosso modo dos conhecimentos das outras áreas. É preciso muito mais que isso, que seja um profissional que consiga 
"passear" pelos diversos caminhos do saber de maneira natural e harmônica envolvendo os conteúdos apresentados numa rede articulada de construção e ampliação do conhecimento. Sendo assim, pode-se perceber que não existe uma definição pronta ou singular sobre o conceito do termo interdisciplinaridade, e sim, várias definições ou conceitos plurais.

Deste modo, os benefícios da utilização de uma abordagem interdisciplinar na prática pedagógica, na qual a interdisciplinaridade é colocada como uma opção para superação da fragmentação do saber é de suma importância para todo o contexto que envolve o ensino-aprendizagem, refletindo positivamente tanto no âmbito escolar como extraescolar.

\section{REFERÊNCIAS}

ALMEIDA, M. E. B. Projeto: uma nova cultura de aprendizagem. 1999. Disponível em: <http://www. proinfo.gov.br>. Acesso em: 04 maio. 2018.

BITTENCOURT, C. M. F. Ensino de História: fundamentos e métodos. São Paulo: Cortez, 2004.

BRASIL. Ministério da Educação. Secretaria de Educação Básica. Diretoria de Currículos e Educação Integral. Diretrizes Curriculares Nacionais Gerais da Educação Básica. Brasília: MEC,2013.

. Ministério da Educação. Secretaria de Educação Média e Tecnológica. Parâmetros Curriculares Nacionais: Ensino Médio. Brasília: Ministério da Educação, 1999, p. 89.

CARLOS, Jairo Gonçalves. Interdisciplinaridade no Ensino Médio: desafios e potencialidades. 2007. Disponível em: http://repositorio.unb.br/bitstream/10482/2961/1/2007 JairoGoncalvesCarl.... Acesso: 13 maio 2018.

DELORS, J. Educação: um tesouro a descobrir. 7. ed. revisada - São Paulo: Cortez, Brasília, DF: UNESCO, 2012.

FAZENDA, I, C, A. integração e interdisciplinaridade no ensino brasileiro: Efetividade ou ideologia. 6. ed. - São Paulo: Edições Loyola, 2011.

- Interdisciplinaridade: história, teoria e pesquisa. 11. ed. Campinas: Editora Papirus, 2003.

FERREIRA, Maria Elisa de M.P. Prólogo: perceber-se interdisciplinar. In: FAZENDA, Ivani Catarina Arantes (org.). Práticas interdisciplinares na escola. São Paulo: Cortez, 2011a, pp. 11-12.

INSTITUTO FEDERAL DE EDUCAÇÃO, CIÊNCIA E TECNOLOGIA DO RIO GRANDE DO NORTE. Projeto Político Pedagógico: uma construção coletiva. Aprovado pela Resolução 38/2012/ CONSUP/IFRN, de 26/03/2012. Natal, 2012.

JAPIASSU, H. Interdisciplinaridade e patologia do saber. Rio de Janeiro: Imago, 1976. 
LUCK, Heloísa. Pedagogia Interdisciplinar: fundamentos teórico-metodológicos. Petrópolis, Rio de Janeiro: Vozes, 1994.

LUDKE. Menga; ANDRÉ, M. E. D. A. Pesquisa em Educação: abordagens qualitativas. 2. ed. Rio de Janeiro: E.P.U., 2017.

MINAYO, Maria Cecília de Souza. O desafio do conhecimento: pesquisa qualitativa em saúde. 8. ed. São Paulo: Hucitec, 2004.

MORAES, M. C. Complexidade e currículo: por uma nova relação. IN: Polis. Santiago: 2010, v. 9, n. 25, p. 289-311, 2010.. Disponível em: https://scielo.conicyt.cl/pdf/polis/v9n25/art17.pdf - Acesso em: 04 out.2018.

MORIN, E. Os sete saberes necessários à educação do futuro. São Paulo: Cortez; Brasília, DF: UNESCO, 2000.

NÓVOA, A. (org.). Os professores e sua formação. Portugal, Dom Quixote:1995.

OLIVEIRA, Emanuelle. Interdisciplinaridade. 2010. Disponível em: http://www.infoescola.com/pedagogia/interdisciplinaridade/. Acesso: 13/05/2018.

SCHÖN, D. Educando o profissional reflexivo. Porto Alegre: Artes Médicas, 2000.

TARDIF, Maurice. Saberes docentes e formação profissional. Petrópolis, RJ: Vozes, 2007.

TEIXEIRA. R. A. Dialogar é preciso: estudos e experiências interdisciplinares na escola. Natal: Editora do. IFRN; Editora do IFG, 2016. 